\title{
PLANEJAMENTO TRIBUTÁRIO COMO FERRAMENTA DE GESTÃO NAS MICRO E PEQUENAS EMPRESAS
}

Raul Pinheiro ${ }^{1}$

Adriana Santos ${ }^{1}$

Lídia Carvalho ${ }^{1}$

Marcus Vinicius Moreira Zittei ${ }^{2}$

\footnotetext{
${ }^{1}$ Gestão Tributária / Lato Sensu / Centro Universitário FECAP

${ }^{2}$ Mestrado em Governança Corporativa / Pós-Graduação / Centro Universitário das Faculdades Metropolitanas Unidas - FMU
} 


\section{PLANEJAMENTO TRIBUTÁRIO COMO FERRAMENTA DE GESTÃO NAS MICRO E PEQUENAS EMPRESAS}

Resumo: O artigo teve como objetivo analisar a importância da implantação do planejamento tributário como ferramenta de gestão dentro das micro e pequenas empresas. Ao longo desse trabalho, realizou-se a pesquisa exploratória e questionários que foram aplicados para sessenta e seis empresas de diferentes ramos de negócios, no período entre outubro e novembro de 2017. A pesquisa revelou que a maior parte dos respondentes, acreditam que os tributos existentes no Brasil não são calculados de forma justa, e que a alta carga tributária é fator de restrição para o lucro da organização. De modo geral, os dados da pesquisa revelaram o quanto é importante a implantação do planejamento tributário como ferramenta de gestão para o processo decisório das empresas, para que se possa minimizar os custos tributários e determinar qual o regime tributário melhor enquadra na operação, estando sempre amparado pela legislação em vigor.

Palavras-chave: Planejamento Tributário. Regimes de Tributação. Simples Nacional. Lucro Presumido. 


\section{Introdução}

O sistema tributário é o complexo formado pelos princípios, normas e regulamentos de um determinado país, que regem e instituem a arrecadação aos órgãos públicos. No Brasil, o sistema tributário é composto por uma Federação, vinte e sete Estados, cinco mil quinhentos e sessenta e quatro municípios, todos, debaixo da constituição Federal tem suas competências de legislar e fiscalizar. Este sistema possui grande número de normas, regulamentos, alíquotas diferenciadas que mudam a todo instante, além das constantes guerras fiscais entre os Estados e Municípios (BRASIL,1988).

Conforme Santana e Domingues (2013), a falta de conhecimento sobre as alterações do mercado, a alta carga tributária, a falta de planejamento e as penalidades, geram custos adicionais as empresas, que terão reflexos diretamente no valor do produto fornecido ao cliente, muitas vezes os impedindo de entrar com estratégias competitivas no mercado. Para Silva et. al (2014), a competitividade mercadológica vem crescendo de forma exponencial no mundo globalizado, exigindo dos gestores atenção as alterações tributárias, para que se antecipem as mudanças, e evitem qualquer possibilidade de falência. Para isto, o planejamento tributário é considerado o melhor caminho para um bom equilíbrio financeiro.

Na pesquisa divulgada pelo SEBRAE (2016), 23,4\% das empresas possuem no máximo dois anos de existência. Isso decorre devido à falta de planejamento, desconhecimento do ramo de atividade e alta carga tributária. Este número é relevante quando vincula esta informação as micro e pequenas empresas, pois estas tendem a investir pouco na busca de informações, ou até mesmo por falta de estrutura física e financeira, acabam não priorizando o que seria a base para um crescimento sustentável.

Para Santana e Domingues (2013), o planejamento tributário quando implantado como ferramenta de gestão permite o empresário enxergar de forma preventiva atos e fatos futuros, com o objetivo de analisar o ônus tributário antes de ocorrer o fato gerador da operação diante de várias opções legais, evitando sempre que possível o procedimento mais oneroso. Observando estes procedimentos é possível verificar gargalos que gerem custos nas empresas, e reduzir, de forma "legal" a tributação, permitindo obter resultados positivos e expansão dos lucros.

Partindo da premissa de que o foco maior dos problemas de fechamento por falta de planejamento está concentrado nas pequenas e médias empresas, a pergunta que norteou para desenvolvimento deste artigo é: Qual a importância da implantação do Planejamento Tributário como ferramenta de gestão dentro das micro e pequenas empresas?

Objetivo geral da pesquisa é analisar a importância da implantação do planejamento tributário dentro das micro e pequenas empresas utilizado como ferramenta de gestão. Os objetivos específicos são: Identificar os regimes de tributações do Lucro Real, Presumido e Simples Nacional; verificar a percepção por parte dos gestores o que é o planejamento tributário e elisão fiscal.

A falta de conhecimento do sistema tributário, o não planejamento de suas atividades e o ônus tributário, tem sido umas das principais causas que a maioria das empresas de pequeno e médio porte, finalizam suas atividades no primeiro ano de funcionamento. Dessa forma, justifica-se para esse tema a importância em identificar através do planejamento tributário as necessidades

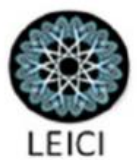


das pequenas e médias empresas em relação à forma de tributação e a comparação de tributos entre os regimes Simples Nacional, Lucro Presumido e Real.

\section{Referencial Teórico}

Nesse capítulo serão abordados os conceitos do planejamento tributário em micro e pequenas empresas, analisando os regimes de Apurações: Lucro Real, Lucro Presumido e Simples Nacional, com breves apontamentos aos Regimes Cumulativos e Não Cumulativos, ICMS e IPI, a importância do Compliance dentro do planejamento tributário e a diferença entre Elisão Fiscal e Evasão Fiscal.

\subsection{Planejamento Tributário}

Conforme comunicado da Receita Federal, o aumento dos tributos está seguindo uma linha crescente, a CTB (carga tributária brasileira) alcançou 32,42\% do PIB em 2014, em 2015 $32,66 \%$, já em 2016 de acordo com analistas da FENACON este número pode ter chegado a $33 \%$ (pela Receita Federal será divulgado no $2^{\circ}$ Semestre de 2017). Estes números apontam que está sendo arrecadado a cada ano uma parcela maior de tributos referente ao que foi produzido dentro do país. (RFB,2016; FENACON, 2017).

O Conselho de Desenvolvimento Econômico e Social define o sistema tributário:

Um sistema tributário nada mais é do que a reunião de um conjunto de impostos, taxas e contribuições por meio dos quais o Estado obtém recursos para o exercício das suas funções básicas, como a oferta de bens e serviços essenciais para o bem-estar da coletividade. É, também, com os recursos arrecadados dos cidadãos que o Estado pode implementar uma política de gastos com implicações redistributivas da renda nacional de um País (CDES, 2009).

O Art. $3^{\circ}$ do Código Tributário Nacional, descreve que o "Tributo é toda prestação pecuniária compulsória, em moeda ou cujo valor nela se possa exprimir, que não constitua sanção de ato ilícito, instituída em lei e cobrada mediante atividade administrativa plenamente vinculada" (CTN,1966). Assim, a Receita Federal declara que o tributo é um instrumento que pode e deve ser utilizado para promover as mudanças e reduzir as desigualdades sociais. O cidadão, consciente da função social do tributo, como forma de redistribuição da renda nacional e elemento de justiça social, é capaz de participar do processo de arrecadação, aplicação e fiscalização do dinheiro público (RFB, 2017).

Siqueira et. al (2011) entendem que o planejamento tributário é o caminho lícito de formalização jurídica de determinada operação, antes da ocorrência do fato gerador, para que o contribuinte prefira a opção que apresente o menor ônus tributário possível. Zanatta e Neto (2006), relatam que para que se possa elaborar de maneira eficiente o planejamento tributário para uma empresa, é necessário saber quais os impostos e as contribuições que as empresas são obrigadas a recolher aos cofres públicos; conhecer as formas de tributação e ter o faturamento, ou seja, quanto a empresa vende por determinado período, seja mensal, semestral, ou anual, é o que se chama de receita bruta.

Vello e Martinez (2014), definem planejamento tributário como um conjunto de ações que proporcionam reduções dos tributos evidentes da empresa, cumprindo dentro dos preceitos das boas práticas de governança corporativa, que não façam progredir outros custos ou tributos

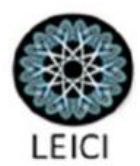


como resultados marginais superiores às reduções alcançadas, realizando maior eficiência tributária ao ser implantada.

Para desenvolver um planejamento tributário adequado, Santana et al. (2014) explicam que a empresa deve estar devidamente organizada contábil e fiscalmente, a fim de ter condições que permitam fornecer elementos necessários à análise de suas atividades. Assim, Corrêa (2006) esclarece que o planejamento deve ser feito com vistas a possibilitar que a empresa pague menos impostos, evitando, no entanto, a evasão fiscal, que, ao contrário de elisão fiscal, consiste em prática que infringe a lei.

\subsection{Micro e Pequenas Empresas}

Segundo a lei complementar 123/06, microempresas possuem faturamento anual de até $\mathrm{R} \$ 360$ mil, e, as pequenas faturam entre $\mathrm{R} \$ 360$ mil e $\mathrm{R} \$$ 3,6 milhões anualmente. Para tanto, a Resolução n 59/98 do Mercosul define que as microempresas faturam até 400 mil dólares (cerca de 940 mil reais), e as empresas de pequeno porte faturam de 400 mil dólares a 3,5 milhões de dólares (cerca de 8,2 milhões de reais) (BRASIL, 2006) (MERCOSUL,1998).

Para o Sebrae (2014), as micro e pequenas empresas são as principais geradoras de riqueza no Comércio no Brasil, já que respondem por $53,4 \%$ do PIB deste setor. No PIB da Indústria, a participação das micro e pequenas $(22,5 \%)$ já se aproxima das médias empresas $(24,5 \%)$. E no setor de Serviços, mais de um terço da produção nacional $(36,3 \%)$ têm origem nos pequenos negócios.

\subsection{Regimes de Apuração}

De acordo com o Decreto 3000/99, LC 123/06 e IN 1700/17, as micro e pequenas empresas podem ser tributadas pelo Simples Nacional, Lucro Presumido, Lucro Real ou Arbitrado, Sistema Cumulativo e Não-cumulativo, desde que os segmentos estejam enquadrados dentro das atividades permissivas ao tipo de tributação. Adiante, faremos uma análise sobre estas tributações (BRASIL, 1999; 2006; 2017).

\subsubsection{Simples Nacional}

O Simples Nacional é um regime compartilhado de arrecadação, cobrança e fiscalização de tributos aplicável às Microempresas e Empresas de Pequeno Porte, previsto na Lei Complementar $\mathrm{n}^{\circ} 123$, de 14 de dezembro de 2006. Abrange a participação de todos os entes federados (União, Estados, Distrito Federal e Municípios). (BRASIL, 2006).

Conforme Paula et al (2017), a Lei Complementar 123/2006, foi criada com objetivo de regulamentar o tratamento diferenciado instituído no artigo 179 da Constituição Federal de 1988, as micro e pequenas empresas, de maneira que houvesse a simplificação na declaração das obrigações acessórias e no recolhimento dos tributos nos âmbitos Federais, Estaduais e Municipais, inclusive os trabalhistas.

Neto et. al (2013) asseveram que é mandamento de natureza constitucional o tratamento tributário diferenciado e favorecido às MPE's e EPP's, definidas pelo Estatuto como os empresários. Todavia, observa-se no campo empresarial a existência de micro e pequenas empresas que não optam pelo Simples Nacional, por haver no Regime Geral o Lucro Presumido ou Lucro Real, alternativas que representam menor ônus tributário.
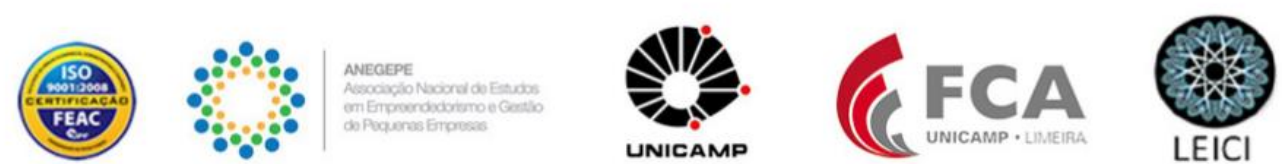
O Simples Nacional implica o recolhimento mensal, mediante documento único de arrecadação (DAS), dos seguintes impostos e contribuições: IRPJ, CSLL, PIS/Pasep, Cofins, IPI, ICMS, ISS e a CPP. Aplica sobre a receita bruta, o tributo calculado a partir das alíquotas nominais constantes nos anexos de I a VI da Lei Complementar 123/06 (art. 18, § $1^{\circ}$ ). Algumas atividades são impeditivas no Simples Nacional. De acordo com os $\S \S 1^{\circ}$ e $2^{\circ}$, do artigo $8^{\circ}$ da Resolução CGSN N 94/2011, o contribuinte deve observar os CNAE (código nacional de atividade econômica) que constam nos anexos V e VI da referida resolução, pois estes são ou poderão não ser permitidos pelo Simples Nacional (BRASIL, 2006; 2011).

\subsubsection{Lucro Presumido}

Segundo Oliveira e Almeida (2015), O Lucro Presumido é uma forma de tributação simplificada, que facilita o cálculo do IR (Imposto de Renda) e da CSLL (Contribuição Social sobre o Lucro Líquido) das pessoas jurídicas. O lucro da empresa é estimado como sendo um percentual do faturamento. Poderão optar por este Regime de tributação, pessoas jurídicas que auferiram receita igual ou inferior a setenta e oito milhões de reais no ano calendário anterior e que não estejam obrigadas a tributação do Lucro Real, conforme orientado no artigo 59 da Instrução Normativa $N^{o}$ 1700/2017, artigo 46 da Lei 10.637/02 e Ato Declaratório Interpretativo SRF $n^{\circ} 05 / 01$.

O IRPJ e a CSLL com base no lucro presumido são apurado trimestralmente, e a opção por este sistema tributário é feita através do pagamento da primeira ou única quota correspondente ao primeiro período apurado dentro do ano calendário vigente, ou da abertura da instituição $\left(\$ \S 4^{\circ}\right.$ e $5^{\circ}$ do Decreto 3000/99).

As vantagens e desvantagens em ser optante pelo lucro presumido:

As vantagens do Lucro Presumido consistem na simplicidade da apuração do IRPJ e da CSLL e na menor quantidade de documentação exigida da empresa por parte do fisco. Como a presunção de lucro é baseada em percentuais fixos, as empresas que possuem lucratividade bem acima do percentual aplicável ao seu ramo de atividade tendem a se beneficiar quando da opção pelo lucro presumido. Entretanto, é necessário verificar se os demais valores a serem adicionados ou excluídos da base de cálculo (como os ganhos de capital e os rendimentos de aplicação financeira) possuem peso significativo na apuração dos valores a pagar. Como desvantagem, além da questão de nem todas as empresas poderem optar, há o fato de que, uma vez que o cálculo efetivo é feito sobre a receita bruta, caso a empresa opere com prejuízo, ela deve, ainda assim, proceder ao recolhimento do IRPJ e da CSLL (CORRÊA, 2006).

De acordo com o art. 26 da IN $n^{\circ} 1700 / 17$, receita bruta abrange as receitas da venda de bens, o preço da prestação de serviços, outras operações não incluídas na atividade da empresa, receita de atividades objetos da empresa, que não sejam venda de bens e serviços. Conforme dispõem o artigo 215 da referida norma citada acima, a presunção do lucro será determinada mediante aplicação dos percentuais permitidos pela lei, relativo a cada atividade auferida, subtraindo as devoluções e vendas canceladas e os descontos incondicionais concedidos (BRASIL, 2017).

Quadro 1: percentuais de presunção para cálculo o IRPJ e CSLL de acordo com as atividades desenvolvidas.

\begin{tabular}{|l|l|l|}
\hline ATIVIDADES & IRPJ & CSLL \\
\hline Organizadores: & & \\
\hline IFGV EAESP & Realizadores:
\end{tabular}




\begin{tabular}{|l|l|l|}
\hline Atividades em geral e equiparadas a serviços médicos hospitalares. & $8 \%$ & $12 \%$ \\
\hline Revenda de combustíveis. & $1,6 \%$ & $12 \%$ \\
\hline Serviços de transporte (exceto o de carga) & $16 \%$ & $12 \%$ \\
\hline Serviços de transporte de cargas & $8 \%$ & $12 \%$ \\
\hline Serviços em geral (exceto serviços hospitalares) & $32 \%$ & $32 \%$ \\
\hline Intermediação de negócios & $32 \%$ & $32 \%$ \\
\hline $\begin{array}{l}\text { Administração, locação ou cessão de bens e direitos de qualquer natureza (inclusive } \\
\text { pessoas jurídicas, exclusivamente prestadoras de serviços, exceto as que prestam } \\
\text { serviços hospitalares e as sociedades civis de prestação de serviços de profissão } \\
\text { legalmente regulamentada, cuja receita bruta anual não ultrapassar R } 120.000,00\end{array}$ & $32 \%$ \\
\hline
\end{tabular}

Fonte: elaborado pelas autoras com base na I.N. 1700/17

Os percentuais que constam no quadro 1, deverão ser aplicados sobre a receita bruta para que o contribuinte encontre a presunção do lucro de acordo com as atividades desenvolvidas. $\mathrm{O}$ percentual de IRPJ que incidirá sobre esta presunção é de $15 \%$ conforme art. 29 da Instrução Normativa 1700/17. Entretanto o contribuinte deve se atentar, quando o valor da multiplicação exceder $\mathrm{R} \$ 120.000,00$ no trimestre, estará sujeito a incidência de adicional do imposto sobre a renda à alíquota de $10 \%$ (dez por cento). O percentual de CSLL que incide sobre a base presumida, varia entre $9 \%, 15 \%, 17 \%$ e $20 \%$ devendo o contribuinte analisar o enquadramento de acordo com a atividade desenvolvida dentro do artigo 30 da IN 1700/17 (BRASIL; 2017).

\subsubsection{Lucro Real}

O Lucro Real é o lucro líquido do exercício ajustado pelas adições, exclusões ou compensações prescritas ou autorizadas pela legislação tributária do Imposto de Renda, ele é determinado a partir do lucro líquido contábil do período de apuração do imposto, com base no que estabelece a legislação comercial. Apesar de algumas receitas lançadas contabilmente não serem tributáveis e de algumas despesas não serem dedutíveis do Imposto de Renda, o Lucro Real é calculado a partir do lucro ou prejuízo contábil, apurada de acordo com a Lei ${ }^{\circ}$ 6.404/76. Somente após a apuração do resultado contábil são feitos os ajustes necessários ao cálculo no Livro de Apuração do Lucro Real - LALUR. (SILVA et.al, 2017).

No lucro real, a base de cálculo do IRPJ e CSLL, será determinada a partir do lucro líquido do período de apuração obtido na escrituração contábil (antes da provisão para o imposto de renda e contribuição social). Primeiro, extrai-se o Lucro Líquido do período, apurado na Demonstração do Resultado do Exercício (DRE); logo após, é feita a escrituração do LALUR, onde são feitos os ajustes (SILVEIRA e ARAUJO, 2014).

A apuração do lucro real envolve maior complexidade para encontrar a base de cálculo dos tributos como IRPJ e a CSLL; e, apurar os demais impostos das entidades. Para que se apure corretamente, o profissional da contabilidade deve analisar uma série de procedimentos, e adotar todos os princípios contábeis; e, ainda lançar todas as provisões necessárias, confecção de todas as demonstrações contábeis como: Balanço Patrimonial, Demonstração de Resultado do Exercício, Demonstrações das mutações do patrimônio líquido, balancetes e livros, o Livro de Apuração do Lucro Real (LALUR) de entrada e saída; e, o Livro Registro de Inventário (CORREIA et.al, 2015).

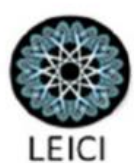




\subsubsection{Regime Cumulativo e Não-Cumulativo}

Segundo Viana (2007), o PIS e a COFINS no regime cumulativo, são tributados à alíquota de $0,65 \%$ e $3 \%$ respectivamente, sobre a receita bruta após subtrair as vendas canceladas e os descontos incondicionais concedidos (Lei 9.715/98 e 9718/98). Apesar de possuírem alíquotas diferenciadas, este sistema de apuração possui incidência em cascata em toda cadeia produtiva, sendo exigido de forma integral em cada operação em que ocorrer o fato gerador, de acordo com a norma tributária vigente, sem a opção de amortização dos tributos pagos nas operações pretéritas.

Para Ribeiro (2007), no sistema não cumulativo o PIS e a COFINS incidem sobre as receitas após dedução das despesas operacionais, o percentual de 1,65\% e 7,6\% respectivamente. Este sistema tributário tem por objetivo reduzir a bitributação através do abatimento do montante de despesas despendido no processo produtivo (matéria-prima, embalagens, aluguel pago a pessoa jurídica, mão de obra, entre outros Lei 10.637/02 e Lei 10.833/03), do valor das receitas auferidas em determinado período, tributando apenas o valor agregado ao produto, com a finalidade de resultar em menor preço.

Viana (2007), defende que um ponto importante da não cumulatividade é que pode ser aplicada apenas nas empresas optantes pelo regime de apuração do Lucro Real. Entretanto, antes de realizar a opção por este regime de tributação, deve-se verificar o montante de despesas dedutíveis, que compense a majoração da alíquota, caso contrário é viável examinar as outras formas de tributação (para os casos permitidos pela lei), pois as alíquotas poderão ser menores e aplicadas diretamente sobre o faturamento mensal.

\subsubsection{ICMS e IPI}

De acordo com a Lei Complementar $n^{\circ} 87$, de 13 de setembro de 1996 (Lei KANDIR), ICMS é o imposto incidente sobre a circulação de mercadorias e serviços de transporte interestaduais e intermunicipais e de comunicações, de competência dos Estados e do Distrito Federal. O imposto é apurado pelo sistema não cumulativo, assegurando ao sujeito passivo o direito de compensar o débito, com o ICMS pagos na entrada de mercadorias e serviços, destinado à sua atividade fim (BRASIL, 1996).

Seguindo as premissas do Decreto $\mathrm{n}^{\circ}$ 7.212, de 15 de junho de 2010, o IPI é o imposto incidente sobre produtos industrializados, nacionais e importados, de competência Federal, obedecendo as especificações da tabela TIPI (Tabela de incidência sobre os produtos industrializados) (BRASIL, 2010).

\subsection{Importância do Compliance no Planejamento Tributário}

Com o crescimento diário de leis e normatizações, obrigações acessórias e exigências do mercado, o programa de "Compliance Tributário" é considerado muito importante dentro do Planejamento Tributário. A palavra "compliance" tem origem do inglês que é interpretado como o dever de cumprir e de estar em conformidade com as exigências. A implantação é feita através da adequação de todos os setores as políticas internas, estabelecimento de controles, prazos e procedimentos de todos os processos (BERTOLLUCI e NASCIMENTO, 2002).

O principal objetivo é combater fraude, corrupção e reduzir os riscos dos negócios através de melhoria dos controles internos, além de agregar transparência a fim de evitar exposições negativas da empresa, melhorando a credibilidade por parte dos clientes, melhor qualidade nos

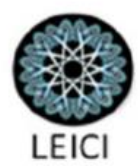


processos, melhoria no retorno de investimentos e no gerenciamento. Estes procedimentos quando controlados de maneira correta, permite a eliminação de multas tributarias, diminui a exposição ao fisco, elimina a insegurança tributaria e melhora as decisões gerenciais (MARQUEZ e MARTINS, 2015).

\title{
2.5 Elisão Fiscal X Evasão Fiscal
}

Segundo Mucci et.al (2011), a elisão fiscal refere-se às práticas lícitas para diminuir a carga tributária, seguindo os princípios legais que impeça a incidência do tributo antes da ocorrência do fato gerador. Carvalho (2013), assevera que um bom planejamento tributário é o caminho para a elisão fiscal, sempre em busca dos melhores resultados para a empresa.

Siqueira et. al (2011) afirma que a evasão, constitui-se na lesão ao fisco, através da não liquidação do tributo devido, ou o pagamento efetuado com valor menor de forma ordenada ou por omissão. A evasão pode ser definida como fraude, que é formada antes do fato gerador com artifícios e simulações no sentido de retirar a incidência do tributo, ou por sonegação, que ocorre depois do fato gerador. Para Carvalho (2013), a evasão fiscal, que é a redução da carga tributária por meios ilegais, tende a impedir ou retardar o fato gerador com o intuito de deixar de recolher o tributo que é devido, isto é classificado como crime de sonegação fiscal perante a legislação brasileira.

$\mathrm{O}$ art. $1^{\circ}$ constitui crime contra a ordem tributária suprimir ou reduzir tributo de acordo com as condutas a seguir:

\begin{abstract}
Omitir informação, ou prestar declaração falsa às autoridades fazendárias; fraudar a fiscalização tributária, inserindo elementos inexatos, ou omitindo operação de qualquer natureza, em documento ou livro exigido pela lei fiscal; falsificar ou alterar nota fiscal, fatura, duplicata, nota de venda, ou qualquer outro documento relativo à operação tributável; elaborar, distribuir, fornecer, emitir ou utilizar documento que saiba ou deva saber falso ou inexato; negar ou deixar de fornecer, quando obrigatório, nota fiscal ou documento equivalente, relativa a venda de mercadoria ou prestação de serviço, efetivamente realizada, ou fornecê-la em desacordo com a legislação Pena reclusão de 2 (dois) a 5 (cinco) anos, e multa (BRASIL, 1990).
\end{abstract}

Oliveira e Gonçalves (2013) relatam que a evasão pode causar prejuízo aos negócios, ao governo e por último à sociedade como um todo. Trata-se de procedimentos ou atitudes adotadas após o fato gerador ocorrido. São exemplos: a omissão de registros em livros fiscais próprios, utilização de documentos incorretos na escrituração contábil e falta de recolhimento de tributos apurados.

\section{Metodologia}

A metodologia utilizada para o desenvolvimento deste estudo é a pesquisa exploratória, que será realizada em leis, artigos científicos, outras publicações e aplicação de questionários nas micro e pequenas empresas. Segundo o ponto de vista de Severino (2007) "A pesquisa exploratória busca apenas levantar informações sobre um determinado objeto, delimitando assim um campo de trabalho, mapeando as condições de manifestação desse objeto. Na verdade, ela é uma preparação para a pesquisa explicativa”.

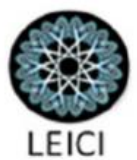


As pesquisas exploratórias, segundo Gil (1999), são apresentadas com o objetivo de permitir uma visão geral, de tipo aproximativo, acerca de determinado fato. Ainda de acordo com o autor, este tipo de estudo proporciona para o pesquisador um maior conhecimento sobre o assunto, a fim de que esse possa elaborar problemas mais precisos ou criar hipóteses que possam ser pesquisadas por estudos posteriores.

\begin{abstract}
A pesquisa bibliográfica é realizada a partir do registro disponível, decorrente de pesquisas anteriores, em documentos impressos, como livros, artigos, teses etc. Utilizam-se dados de categorias teóricas já trabalhadas por outros pesquisadores e devidamente registrados. Os textos tornam-se fontes dos temas a serem pesquisados. O pesquisador trabalha a partir de contribuições dos autores dos estudos analíticos constantes dos textos. (SEVERINO, 2007, p. 122).
\end{abstract}

Gil (1999) relata que a principal vantagem da pesquisa bibliográfica consiste no fato de permitir ao investigador a cobertura de um conjunto de fenômenos muito maior do que aquele que poderia pesquisar diretamente. Esta vantagem se torna particularmente importante quando o problema de pesquisa exige dados difundidos pelo espaço.

O questionário foi aplicado entre outubro e novembro de 2017, como instrumento de pesquisa para as pequenas e médias empresas por de e-mail através do link https://docs.google.com/forms/d/1ZpDroO4TR6MeiDGEv8VeLxlWibYMzTjIxOkVoJsK4D8 /editpDroO4TR6MeiDGEv8VeLxlWibYMzTjIxOkVoJsK4D8/edit. Constituído por 16 assertivas, onde avaliaram as questões de acordo com as indicações Discordo Totalmente, Concordo Totalmente, Indiferente, Concordo Parcialmente e Discordo parcialmente atribuída pela Escala Likert.

É uma escala não-comparativa, enumerada que pode ser utilizada para avaliar produtos e serviços, usualmente encontrada em questionários de pesquisa de mercado, por ser de simples construção e fornecer liberdade para que os seus respondentes expressem suas convicções, assinalando um único item de acordo com seu grau de satisfação (LIKERT, 1932). O questionário é uma técnica usada para identificar opiniões, crenças e sentimentos sobre um determinado assunto. É apresentado de forma escrita, estruturado com perguntas que podem ser abertas e ou fechadas (GIL,1999).

\title{
4 Análise e Discussão dos Resultados
}

Para coleta dos dados dessa pesquisa, foi aplicado um questionário, no qual 66 respondentes participaram. A enquete está dividida em Parte 1 - perfil da empresa (quadro 2), e Parte 2 afirmativas (quadro 3). No quadro 3, para fins de análise foi somado os resultados do concordo totalmente e parcialmente, e discordo totalmente e parcialmente para que os resultados sejam apresentados de maneira objetiva.

\section{Quadro 2: Perfil da empresa}




\begin{tabular}{|c|c|c|c|c|c|}
\hline $\begin{array}{l}\text { Atividade } \quad \text { da } \\
\text { empresa }\end{array}$ & $\frac{32,31 \%}{\text { Comércio }}$ & $\begin{array}{l}\frac{55,38 \%}{\text { Prestação }} \\
\text { Serviço }\end{array}$ & $\frac{6,15 \%}{\text { Indústria }}$ & $\frac{3,08 \%}{\text { Outros }}$ & $\begin{array}{l}\frac{3,08 \%}{\text { Comércio }}+ \\
\text { prestação de } \\
\text { serviços }\end{array}$ \\
\hline $\begin{array}{l}\text { Regime tributário } \\
\text { da empresa }\end{array}$ & $\frac{71,2 \%}{\text { Simples Nacional }}$ & $\frac{12,1 \%}{\text { Lucro Real }}$ & $\frac{16,7 \%}{\text { Lucro Presumido }}$ & & \\
\hline $\begin{array}{l}\text { Cargo que exerce } \\
\text { dentro da empresa }\end{array}$ & $\frac{33,3 \%}{\text { Diretor }}$ & $\frac{18,2 \%}{\text { Outros }}$ & $\begin{array}{l}22,7 \% \\
\text { Gerente }\end{array}$ & $\begin{array}{l}15,2 \% \\
\text { Supervisor }\end{array}$ & $\frac{10,6 \%}{\text { Contador }}$ \\
\hline $\begin{array}{ll}\begin{array}{l}\text { Quantidade } \\
\text { colaboradores }\end{array} & \mathrm{de} \\
\end{array}$ & $\frac{31,8 \%}{\text { até } 5}$ & $\frac{21,2 \%}{\text { acima de } 20}$ & $\frac{6,1 \%}{\operatorname{de~} 6 \text { a } 10}$ & $\frac{3,0 \%}{\text { de } 11}$ a 15 & $\frac{37,9 \%}{\text { de } 16 \text { a } 20}$ \\
\hline Faturamento anual & $\begin{array}{l}\frac{30,3 \%}{1.000,00} \\
200.000,00\end{array}$ & \begin{tabular}{|l|}
$50 \%$ \\
$1.000 .000,01$ \\
$5.000 .000,00$
\end{tabular} & \begin{tabular}{|l|}
$10,6 \%$ \\
$5.000 .000,01$ \\
$10.000 .000,00$
\end{tabular} & \begin{tabular}{|l|}
$\frac{9,1 \%}{200.000,01 \quad a}$ \\
$1.000 .000,00$ \\
\end{tabular} & \\
\hline
\end{tabular}

Fonte: Dados da pesquisa

De acordo com o quadro 2, 32,31\% (21) dos respondentes, possuem como atividade principal o comércio enquanto outros 55,38\% (36) dizem ter como atividade principal a prestação de Serviços. 6,15\% (4) possuem indústria, 3,08\% (2) responderam outros, e 3,08\% (2) responderam comércio mais prestação de serviços como atividade empresarial. Um dos entrevistados não respondeu a esta questão. Observou-se que a maioria $71,2 \%$ (47) dos respondentes são do regime Simples Nacional enquanto $12,1 \%$ (8) estão sob o regime do Lucro Real e $16,7 \%$ (11) sob o Lucro presumido.

Ainda no quadro 2, identificou-se que 33,3\% (22) dos respondentes são diretores e 66,7\% (44) ocupam outros cargos dentro da organização. Em relação a quantidade de funcionários, 31,8\% (21) possuem até 5 funcionários enquanto 21,2\% (14) possuem mais de 20 colaboradores. De acordo com os dados, $50 \%$ (33) responderam que o faturamento é de $1.000 .000,01$ a $\mathrm{R} \$$ $5.000 .000,00$ enquanto $30,3 \%$ (20) das empresas tem seu faturamento anual de $\mathrm{R} \$ 1.000,00 \mathrm{a}$ $200.000,00$.

\section{Quadro 3: Afirmativas}

\begin{tabular}{|l|l|l|l|}
\hline Questões & Concordo & Discordo & Indiferente \\
\hline Considero os tributos existentes no Brasil calculados de forma justa & 9 & 56 & 1 \\
\hline $\begin{array}{l}\text { A empresa utiliza-se de planejamento tributário para economizar } \\
\text { tributos }\end{array}$ & 25 & 38 & 6 \\
\hline $\begin{array}{l}\text { O empresário possuía conhecimento prévio sobre os tributos que } \\
\text { teriam incidência sobre a atividade empresarial antes de iniciar o } \\
\text { empreendimento. }\end{array}$ & 26 & 33 & 7 \\
\hline $\begin{array}{l}\text { Os impostos ocupam parcela significativa do custo do } \\
\text { produto/prestação de serviço. }\end{array}$ & 59 & 6 & 1 \\
\hline $\begin{array}{l}\text { A carga tributária brasileira é fator de restrição para o lucro da } \\
\text { organização }\end{array}$ & 59 & 6 & 1 \\
\hline
\end{tabular}




\begin{tabular}{|l|l|l|l|}
$\begin{array}{l}\text { A empresa já fez uso de algum planejamento objetivando reduzir os } \\
\text { impactos tributários }\end{array}$ & 25 & 35 & 6 \\
\hline $\begin{array}{l}\text { O planejamento tributário é uma ferramenta importante que as } \\
\text { empresas podem ter para diminuir os gastos com tributos }\end{array}$ & 59 & 2 & 5 \\
\hline Planejamento Tributário confunde-se com sonegação fiscal. & 17 & 42 & 7 \\
\hline $\begin{array}{l}\text { A implementação do planejamento tributário aumentaria os custos e } \\
\text { despesas da empresa }\end{array}$ & 24 & 36 & 6 \\
\hline $\begin{array}{l}\text { O processo de tomada de decisão ficaria mais prático e rápido, após a } \\
\text { adoção do Planejamento Tributário }\end{array}$ & 56 & 1 & 9 \\
\hline $\begin{array}{l}\text { Se a carga tributária nacional fosse menor, a empresa teria um lucro } \\
\text { maior }\end{array}$ & 63 & 3 & 0 \\
\hline
\end{tabular}

Fonte: Dados da pesquisa

De acordo com o quadro 3, 84,8\% (56) destes consideram que os tributos existentes no Brasil não são calculados de forma justa, $89,4 \%$ (59) identificaram que os impostos ocupam parcela significativa do custo, e que a carga tributária brasileira é fator de restrição do lucro dentro das organizações. Silva e Filho (2012) argumentam que a questão tributária tem exigido a cada dia maior atenção das organizações, pois se a empresa não conseguir repassar toda a carga tributária a seus preços, o resultado líquido decresce, interferindo em sua capacidade de investimentos, até mesmo na reposição dos níveis já alcançados.

Entre os respondentes, apenas 37,9\% (25) utilizam ou já usufruíram do planejamento tributário para diminuição da carga tributária empresarial. Entretanto 89,4\% (59) dos participantes tem ciência que o planejamento tributário é uma ferramenta importante na diminuição dos gastos tributários. Oliveira e Gonçalves (2013) relatam que para se obter sucesso nos negócios perante uma economia tão instável como a nossa, as empresas necessitam de ferramentas seguras e amparadas pela legislação que resultam ao contribuinte em menor carga tributária e que racionalizem os seus custos tributários.

Conforme o quadro 3, dos sessenta e seis representantes empresariais que responderam, 84,9\% (56) acreditam que o processo de tomada de decisão fica mais prático e rápido, após a adoção do planejamento tributário. Silva (2014) explica isto ao citar que o planejamento tributário ajuda a empresa a obter êxito no cumprimento de deveres, evitando que paguem tributos desnecessários, acelerando os processos administrativos e operacionais, permitindo obter melhor controle do fluxo de caixa e visão integrada dos custos da empresa; consequentemente estes resultados influenciam no preço final do produto ou serviço e torna a empresa mais competitiva.

\section{Conclusão}

O objetivo geral desse estudo é verificar a importância da implantação do Planejamento Tributário como ferramenta de gestão dentro das pequenas e médias empresas. Foi atingido de forma favorável, de acordo com o questionário respondido pelos representantes empresariais das micro e pequenas empresas. Apesar de apenas 37,9\% (25) utilizar ou já ter usufruído do planejamento tributário para reduzir os impactos tributários, 89,4\% (59) reconhecem que o planejamento tributário é uma ferramenta muito importante para minimizar custos tributários,

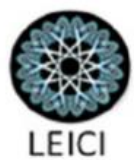


e $84,84 \%$ (56) tem ciência que o processo de tomada de decisão ficaria mais prático e rápido, aderindo ao planejamento.

Os objetivos específicos desse artigo, foram identificar os regimes de tributações do Lucro Real, Presumido e Simples Nacional e verificar a percepção por parte dos gestores o que é o planejamento tributário e elisão fiscal. Identificou-se que $71,2 \%$ dos respondentes são do Regime Simples Nacional, 16,7\% do lucro presumido e 12,1\% do lucro real. No Brasil, existe uma carência quanto a conscientização dos empresários sobre as tributações existentes dentro do seu ramo de atividade, 50\% (33) dos respondentes afirmaram não possuir conhecimento prévio da tributação da empresa antes da abertura.

No entanto, 89,4\% (59) identificaram que os impostos ocupam parcela significativa do custo, e que a carga tributária brasileira é fator de restrição do lucro dentro das organizações. Estes dados comprovam que o problema do fechamento das micro e pequenas empresas, está na falta de planejamento, desconhecimento do ramo de atividade e alta carga tributária, ou seja, não buscam antes do fato gerador conhecer melhor a atividade e sua respectiva carga tributária.

A carga tributária no Brasil é elevada, os respondentes concluem que se a carga tributária nacional fosse menor, a empresa teria melhores lucros, $84,8 \%$ (56) destes consideram que os tributos existentes no Brasil não são calculados de forma justa. Por meio da pesquisa, acreditase que o cenário do mundo globalizado, exige dos profissionais maior transparência dos seus negócios e diminuição dos custos para manter preços competitivos no mercado. O planejamento tributário, conforme os respondentes permitem a empresa visualizar os gargalos através da análise minuciosa dos processos internos e o conhecimento dos tipos de tributação existentes, podendo minimizar custos agregados ao processo.

Houve uma limitação do estudo sobre o planejamento tributário em microempresas devido à restrição de pesquisas sobre a existência ou não da implantação desta ferramenta de gestão. Uma sugestão para trabalho futuro é dar continuidade a pesquisa sobre o Compliance Tributário em micro e pequenas empresas, verificando a viabilidade da implantação. Este presente estudo contribui para ampliação do conhecimento acadêmico sobre o sistema tributário nas micro e pequenas empresas, assim como para a conscientização da área empresarial e profissional quanto a importância desta ferramenta como parte do sistema de gestão, para melhor gerenciamento dos custos tributários.

\section{Referências}

BERTOLUCCI,A.V.; NASCIMENTO, D.T. Quanto custa pagar tributos?. Revista Contabilidade \& Finanças, v.13, n.29, 2002.

BRASIL. Constituição da República Federativa do Brasil de 1988. Disponível em: http://www.planalto.gov.br/ccivil_03/constituicao/douconstituicao88.pdf. >. Acesso em: 18. ago. 2017.

. Lei n. 5.172, de 25 se Outubro de 1966. Dispõe sobre o Sistema Tributário Nacional e institui normas gerais de direito tributário aplicáveis à União, Estados e Municípios. Disponível em: http://www.planalto.gov.br/ccivil_03/leis/L5172.htm>. Acesso em 08.set.2017. 
Lei n. 123 de 14 de Dezembro de 2006. Institui o Estatuto Nacional da Microempresa

e da Empresa de Pequeno Porte; Disponível em: http://www.planalto.gov.br/ccivil_03/leis/LCP/Lcp123.htm>. Acesso em 08.set.2017.

. Resolução CGSN n. 94 de 29 de Novembro de 2011. Dispõe sobre o Simples Nacional e dá outras providências; Disponível em: http://normas.receita.fazenda.gov.br/sijut2consulta/link.action?idAto $=36833 \& v i s a 0=$ anotado $>$ . Acesso em 08.set.2017.

Lei n. 8.137, de 27 de Dezembro de 1990. Define crimes contra a ordem tributária, econômica e contra as relações de consumo, e dá outras providências. Disponível em: http://www.planalto.gov.br/ccivil_03/leis/L8137.htm>. Acesso em 27.set.2017.

Instrucão Normativa n. 1700, de 14 de Marco de 2017. Dispõe sobre a determinação e o pagamento do imposto sobre a renda e da contribuição social sobre o lucro líquido das pessoas jurídicas e disciplina o tratamento tributário da Contribuição para o PIS/Pasep e da Cofins no que se refere às alterações introduzidas pela Lei ${ }^{\circ} 12.973$, de 13 de maio de 2014 . Disponível em: http://normas.receita.fazenda.gov.br/sijut2consulta/link.action? idAto $=81268 \&$ visão=anotado. $>$ Acesso em 27.set 2017 .

Decreto n. 3.000, de 26 de Março de 1999. Regulamenta a tributação, fiscalização, arrecadação e administração do Imposto sobre a Renda e Proventos. Disponível em: http://www.planalto.gov.br/ccivil_03/decreto/d3000.htm >. Acesso em 27.set.2017.

Lei Complementar n. 87, de 13 de Setembro de 1966. Dispõe sobre o imposto dos Estados e do Distrito Federal sobre operações relativas à circulação de mercadorias e sobre prestações de serviços de transporte interestadual e intermunicipal e de comunicação, e dá outras providências. (LEI KANDIR). Disponível em: http://www.planalto.gov.br/ccivil_03/leis/LCP/Lcp87.htm. Acesso em 30.set.2017.

Decreto n. 7.212, de 15 de Junho de 2010. Regulamenta a cobrança, fiscalização, arrecadação e administração do Imposto sobre Produtos Industrializados - IPI. Disponível em: http://www.planalto.gov.br/ccivil_03/_ato2007-2010/2010/decreto/d7212.htm. Acesso em 30.set.2017.

CARVALHO, K. W. Planejamento Tributário com ênfase em uma empresa revendedora de combustíveis: Um estudo de caso da empresa K. Revista Científica Semana Acadêmica. Fortaleza, v. 1, n. 36, 2013.

CDES. Conselho de Desenvolvimento Econômico e Social. Indicadores de Equidade do Sistema Tributário Nacional. Brasília, CDES, 2009. Disponível em: http://www.ipea.gov.br/portal/index.php?option=com_content\&view=article\&id=5642. Acesso em 27.set.2017. 
CORRÊA, A. C. M. Planejamento Tributário: ferramenta estratégica da gestão empresarial. Revista Brasileira de Contabilidade, n. 158, 2006.

, J. O. Planejamento Tributário. Boletim Jurídico, Uberaba/MG, a. 4, no 183, 2006.

P.C.; SILVA, B. A.; CONCEIÇÃO. A. M.; ASSIS ,A. E. As empresas optantes ao simples nacional: Vantagens e Desvantagens entre o lucro presumido e o Lucro real. RACRERevista de Administração, v.15, n. 19, 2015.

FENACON. Carga tributária deve alcançar cerca de $33 \%$ do PIB do País ao final do ano. 2017. Disponível em: http://fenacon.org.br/noticias/carga-tributaria-deve-alcancar-cerca-de33-do-pib-do-pais-ao-final-do-ano-1532/utm_source=akna\&utm_mediu=email\&utm_cam Paign=Press+Clipping+Fenacon+21+de+fevereiro+de+2017>Acesso em: 27.set.2017.

GIL, A. C. Métodos e técnicas de pesquisa social. 5.ed. São Paulo: Atlas, 1999.

LIKERT, R. A Technique for the Measurement of Attitudes. Archives of psychology. 1932; $22(140) ; 1-55$.

MARQUEZ, C. M.; MARTINS, V. F. Em busca da transparência: entendendo os conceitos de governança corporativa. Revista E- Locução, v.08, n.4, 2015.

MERCOSUL. Resolução $\mathbf{n}^{\circ} 59$ de 1998. Políticas de apoio às micro, pequenas e médias empresas do Mercosul. Etapa II. Disponível em: http://www.mercosur.int/msweb/portal\%20intermediario/Normas/normas_web/Resoluciones/ PT/Res_059_098_Política\%20Apoio\%20Pequen\%20Média\%20Empresas_Ata\%204_98.PDF >. Acesso em: 27.set.2017.

MUCCI, D. M.; HORTA, R. A. M.; FARIA, B. R.; NETO, M. R. Planejamento tributário aliado à gestão financeira eficaz: Estudo de caso de uma empresa de porte médio do setor atacadista baseado em análises de regime de tributação. In: XIV SEMEAD: Seminários em Administração FEA-USP, 2011, São Paulo. Anais eletrônicos... SEMEAD, 2011.

NETO, A. M. C, FREITAS, I. R.; NEVES, L. P.; COSTA, L. R. Simples Nacional: um estudo de análise tributária após lei complementar 147/2014 Diálogos em Contabilidade: teoria e prática, v. 1, n. 1, edição 1, jan./dez. 2013.

OLIVEIRA, R. R. F.; ALMEIDA. J. P. Planejamento Tributário de uma Empresa Prestadora de Serviços na Área de Ensino. Revista Científica e-Locução, v. 1, n. 5, 2015.

R. R. F.; GONÇALVES. M. A importância do Planejamento Tributário para as empresas. Revista Científica e-Locução, v 1 n. 3, 2013. 
PAULA, R. M.; COSTA, D. L.; FERREIRA, M.P. A Percepção da Carga Tributária nas Micro e Pequenas Empresas antes e após o Simples Nacional. Revista da Micro e Pequena Empresa, v. 11, n. 1, 2017.

RECEITA FEDERAL. Carga Tributária Bruta atinge 32,66 \% do PIB em 2015. 2016. Disponível em: https://idg.receita.fazenda.gov.br/noticias/ascom/2016/setembro/cargatributaria-bruta-atinge-32-66-do-pib-em-2015-1 >. Acesso em: 17 ago. 2017.

Educação Fiscal. Disponível em: http://idg.receita.fazenda.gov.br/acessorapido/direitos-e-deveres/educacao-fiscal> . Acesso em:07.set.2017.

RIBEIRO, R. K. O princípio da não-cumulatividade no Direito Tributário Brasileiro. Revista de Doutrina TRF-4, n.18 , 2007

SANTANA, F. S.; FERREIRA, J. R.; HERMSDORFF, L. L.; OLIVEIRA, M.C.; AQUINO, A. P. Planejamento Tributário como Ferramenta na Gestão Empresarial, Revista eletrônica das faculdades sulamerica, $v 6,2014$.

.B. J.; DOMINGUES, G. A importância do planejamento tributário nas pequenas empresas não optantes pelo simples nacional. Revista Científica Semana Acadêmica. v. 1, n. 44, Fortaleza, 2013.

SEBRAE. Sobrevivência das empresas no Brasil. 2016. Disponível em: http://www.sebrae.com.br/Sebrae/Portal\%20Sebrae/Anexos/sobrevivencia-das-empresas-nobrasil-relatorio-2016.pdf acessado em>. Acesso em: 17. ago. 2017.

Serviço Brasileiro de Apoio às Micro e Pequenas Empresas. Micro e Pequenas

Empresas Geram 27\% do PIB do Brasil (2014). Disponível em: http://www.sebrae.com.br/sites/PortalSebrae/ufs/mt/noticias/micro-e-pequenas-empresasgeram-27-do-pib-do-brasil,ad0fc70646467410VgnVCM2000003c74010aRCRD> Acesso em: 27.set.2017.

SEVERINO, A. J. Metodologia do trabalho científico. 21.ed. São Paulo: Cortez, 2000.

SILVA, F. A. O.; CARPINETTI, M. F.; SILVA, B. M. F. T.; ALVARELI, L. V. G. A importância do planejamento tributário nas empresas mediante a complexa carga tributária brasileira. Janus, v. 8, n. 13, 2014.

J.; SILVA. M. G.; IZIDIO, S. S. G.; CAETANO, V. M.; ANDRADE, R. R. A. As principais mudanças no Simples Nacional para 2018 Revista FAROL - Rolim de Moura RO, v. 5, n. 5, 2017. 
T. B. J.; FILHO, R. N. L. A carga tributaria é fator de restrição para o lucro organizacional? Um olhar empresarial sobre a teoria das restrições. Revista Pensamento Contemporâneo em Administração, v.6, n.2, 2012.

SILVEIRA, G. P.; ARAUJO. N. P. L. Planejamento Tributário: Estudo de caso sobre a aplicação do regime de tributação menos oneroso para um posto de gasolina na cidade de Natal/ RN. Revista Eletrônica Diálogos Acadêmicos, n 2, v.7, 2014.

SIQUEIRA, E. B.; CURY, L. K. P.; GOMES, T. S. Planejamento tributário. Revista CEPPG CESUC, n. 25, v.2, p.184-196, 2011.

VELLO, C. P. A.; MARTINEZ, L. A. Planejamento tributário eficiente: Uma análise de sua relação com o risco de mercado. Revista Contemporânea de Contabilidade. v. 11.2014.

VIANA, L. S. A cumulatividade e a não cumulatividade do PIS e da COFINS. Revista Gestão e Conhecimento, v. 3, n. 2, 2007

ZANATTA, D.; NETO, R. M. Algumas considerações sobre o planejamento tributário: uma comparação por meio de simulação entre o Simples, o Lucro Presumido e o Lucro Real. Revista de Ciências Gerenciais, v. 10, n. 12, 2006. 